\title{
Experimental Study on Microwave Assisted Hard Rock Cutting of Granite
}

\author{
Philipp Hartlieb ${ }^{1}$ and Bruno Grafe ${ }^{2}$ \\ ${ }^{1}$ Chair of Mining Engineering and Mineral Economics, Montanuniversitaet Leoben, Leoben, Österreich \\ ${ }^{2}$ Institute of Mining and Special Civil Engineering, Freiberg University of Mining and Technology, Freiberg, \\ Deutschland
}

Published online January 5, 2017

\begin{abstract}
This paper describes the influence of high-power microwave irradiation on the forces needed to cut granite with a conical pick. Granite samples have been irradiated with $24 \mathrm{~kW}$ at $2450 \mathrm{MHz}$ with an open ended waveguide. The effect of microwave treatment was assessed by linear cutting tests with a conical pick.

Microwave irradiation lead to an extensive network of cracks. The linear cutting tests provide a comparison of treated and non-treated parts and show that peak as well as average forces needed for cutting this very hard and abrasive material are reduced significantly. The average cutting force is reduced from 7.06 to $6.39 \mathrm{kN}$, equalling $10 \%$, from the untreated to the irradiated part, respectively.
\end{abstract}

Keywords: Microwave irradiation, Rock cutting, Alternative rock breakage, Alternative excavation

Experimentelle Untersuchungen zum mikrowellenunterstützten Hartgesteinsschneiden am Beispiel von Granit

Zusammenfassung: Diese Arbeit beschreibt den Einfluss von Hochenergie-Mikrowellenbestrahlung auf die beim Schneiden von Granit auftretenden Kräfte. Granitproben wurden mit Mikrowellen bei $2450 \mathrm{MHz}$ mit $24 \mathrm{~kW}$ mit einem offenen Hohlleiter bestrahlt. Der Effekt dieser Bestrahlung wurde mit einem linearen Schneidprüfstand bestimmt.

Es zeigt sich, dass die Mikrowellenbestrahlung zu einem ausgeprägten Rissnetzwerk im Gestein führt. Die durchgeführten Schneidversuche an mit Mikrowellen behandelten und unbehandelten Bereichen zeigen, dass sowohl die gemessenen Spitzen- als auch die Durchschnittskräf-

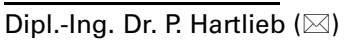

Chair of Mining Engineering and Mineral Economics,

Montanuniversitaet Leoben,

Franz Josef Strasse 18,

8700 Leoben, Österreich

philipp.hartlieb@unileoben.ac.at te durch die Bestrahlung deutlich reduziert werden. Die durchschnittliche Schneidkraft verringert sich demnach von 7,06 im unbestrahlten auf 6,39 kN im bestrahlten Bereich. Dies entspricht eine Reduktion der Kräfte von $10 \%$.

Schlüsselwörter: Mikrowellenbestrahlung,

Hartgesteinsgewinnung, Schneidkraft, Alternative

Gesteinszerkleinerung

\section{Introduction}

Hard rock cutting and mechanical excavation are common and widespread technologies that show a number of advantages over drilling and blasting technologies. Major amongst them is the continuous excavation instead of the blasting cycle. Extraction and loading takes place simultaneously, haulage can also be conducted while excavating. Furthermore, the surrounding rock mass is affected less, increasing safety as well as making scaling redundant. No blasting gases need to be vented and blasting noise does not apply to adjacent communities. The material excavated appears in a relatively distinct particle size distribution. Possible economic advantages in this regard are at handneither is the material pre-sized, nor do boulders affect the haulage chain's effectivity. The major disadvantage, however, is the limitation of mechanical excavation machines to geotechnical conditions exceeding a certain abrasivity and rock strength. The aim of numerous research and innovation activities therefore is to overcome these barriers and to enable the technology to work efficiently also in tough conditions.

Firstly, this can be achieved by improving the quality of the cutting tools for example by introducing silicon carbide and diamond inserts. Secondly, completely new cutting concepts and principles are under consideration and development. These new concepts range from changing the cutting geometries to activation of the tool with artificial 

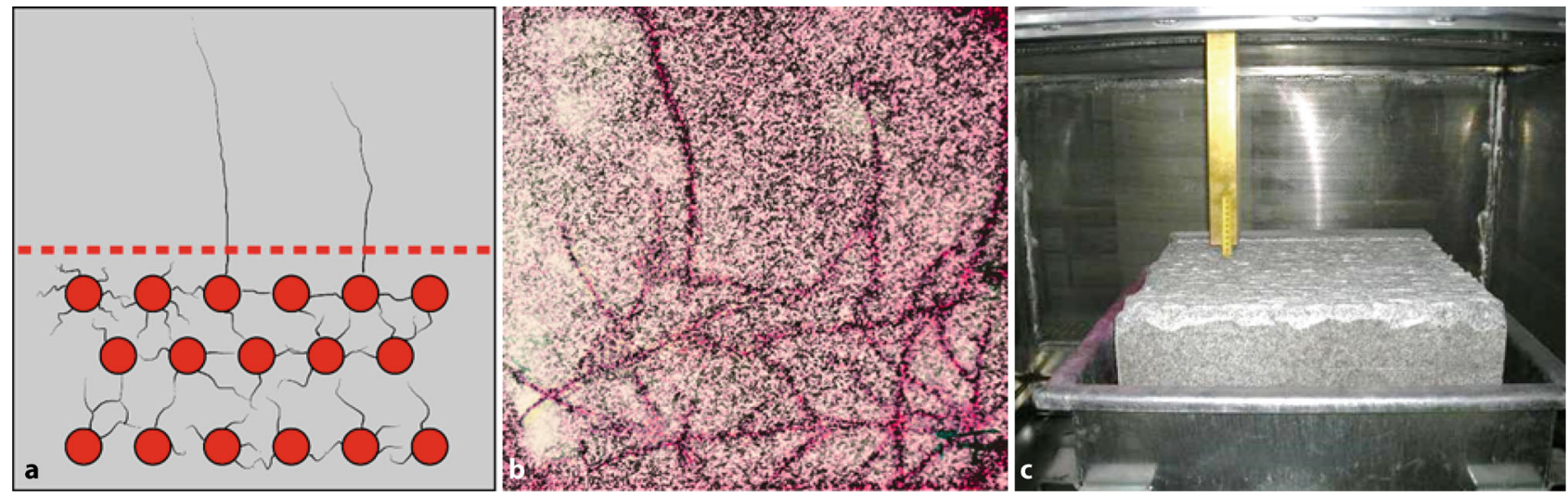

Figure 1: Radiation pattern (left); Crack distribution (middle); Radiation chamber with waveguide (right)

vibrations, undercutting and others. One third promising approach is to pre-weaken the rock mass in order to reduce the cutting resistance by introducing artificial cracks e.g. with the help of selective microwave irradiation.

Microwave treatment of rocks is driven by the absorption of microwaves by the rock, leading to a conversion of the electromagnetic energy into heat. Unlike classical convective heating, the heat flux is directly induced inside the material. Furthermore, different minerals show varying microwave absorbing abilities. These effects introduce temperature gradients into the rock that generate stress, which can exceed the strength of the rock, leading to the occurrence and propagation of cracks. The ability to transfer and absorb microwaves in a dielectric material is described by the complex dielectric constant $\epsilon$ (permittivity):

$$
\epsilon=\epsilon_{\mathrm{r}}+\mathrm{i} \epsilon_{\mathrm{i}}=\epsilon_{0}\left(\kappa_{\mathrm{r}}+\mathrm{i} \kappa_{\mathrm{i}}\right),
$$

where $\epsilon_{0}$ defines the permittivity of vacuum, $\kappa_{\mathrm{r}}$ the real part of the relative permittivity and $\kappa_{\mathrm{i}}$ the imaginary part. The absorption of microwave energy within the material is mainly governed by $\kappa_{\mathrm{i}}$. According to Santamarina [1] typical values for hard rocks range from $10^{-3}-50$ for $\kappa_{i}$ and $2-10$ for $\kappa_{r}$ depending on various parameters (rock type, mineral distribution, microwave frequency, temperature, water content, ...). Since rocks contain several minerals arranged in various distributions, different $\kappa_{\mathrm{i}}$ values appear in the material on the microstructure level. Typically well microwave absorbing minerals are plagioclase $\left(\kappa_{\mathrm{i}}=0.004\right.$ $0.32)$, pyroxene $\left(\kappa_{\mathrm{i}}=1.62\right)$ and ilmenite $\left(\kappa_{\mathrm{i}}=32.58\right)$ whereas quartz $\left(\kappa_{\mathrm{i}}=0.0006-0.0033\right)$, orthoclase $\left(\kappa_{\mathrm{i}}=0.00019\right)$ and muscovite $\left(\kappa_{\mathrm{i}}=0.0006-0.0034\right)$ are poorly absorbing. Consequently, an inhomogeneous thermal field on the grain level is expected. Recently, several numerical studies of rocks with heterogeneous microstructures showed that the resulting stresses around the phase boundaries of strongabsorbing particles are high enough to initiate cracks which can propagate further into the material [2-8]. It was already demonstrated that these thermally induced cracks may lead to a significant reduction in resistance during size reduction in comminution processes [9].

Despite the advances in microwave supported mineral processing no information is yet available on the possibili- ties of the technology in mechanical excavation. This paper will therefore introduce a combination of microwave preweakening and mechanical excavation with a conical pick and provide insights into the associated damage mechanisms.

\section{Methods and Material}

\subsection{Rock Samples}

The described tests were performed on so called "Neuhauser Granite". This granite is composed of $27 \%$ quartz, $53 \%$ feldspar and $20 \%$ micas. Single minerals can be up to $4 \mathrm{~mm}$ in size. The texture is granular with some xenomorphic crystals. The rock shows a uniaxial compressive strength of $210 \mathrm{MPa}$ and a Cerchar abrasivity index of 4.2. Completely intact (crack free) samples were cut to blocks of $50 \times 50 \times 30 \mathrm{~cm}$ for further investigations.

\subsection{High-power Microwave Irradiation}

The high-power microwave irradiation was performed with a $24 \mathrm{~kW}$ microwave source operating at a frequency of $2450 \mathrm{MHz}$ with an open ended waveguide directed at the rock surface. The apparatus allows for treating blocks with dimensions of $50 \times 50 \times 30 \mathrm{~cm}(30 \mathrm{~cm}$ in depth). The precisely moveable $x$ - $y$-table enables irradiating specific spots at the rock surface. Corresponding to the size of the waveguide, these spots have dimensions of approximately $5 \mathrm{~cm}$ in diameter.

Irradiation tests were performed in a chessboard-like pattern consisting of three lines. Two lines had a spacing of $4.5 \mathrm{~cm}$ towards each other, the third one $9 \mathrm{~cm}$. Each of the red spots in the figure represents an irradiation spot. The spacing between the spots in one row was $7.5 \mathrm{~cm}$. The lines represent the cracks emerging from those irradiation spots as can be seen in the photograph. The irradiation parameters were chosen to be $24 \mathrm{~kW}$ with $2450 \mathrm{MHz}$ for a time of $30 \mathrm{~s}$ at each spot (Figure 1). 
Figure 2: Linear rock cutting stand HSX 1000-50 of TU Bergakademie Freiberg
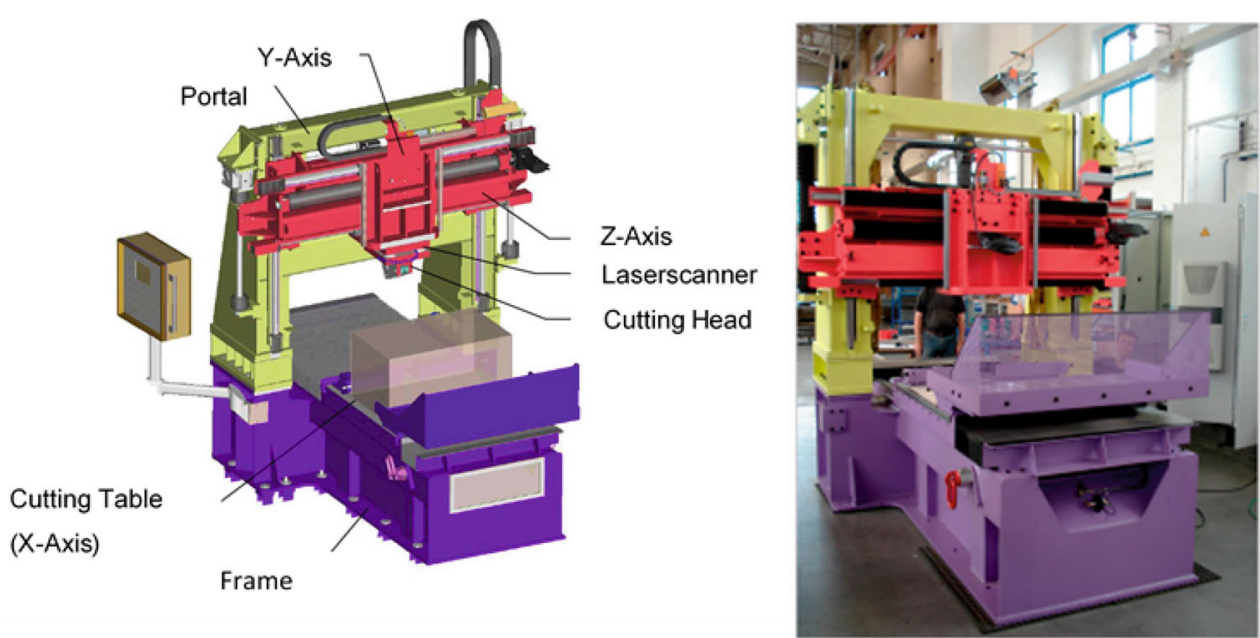
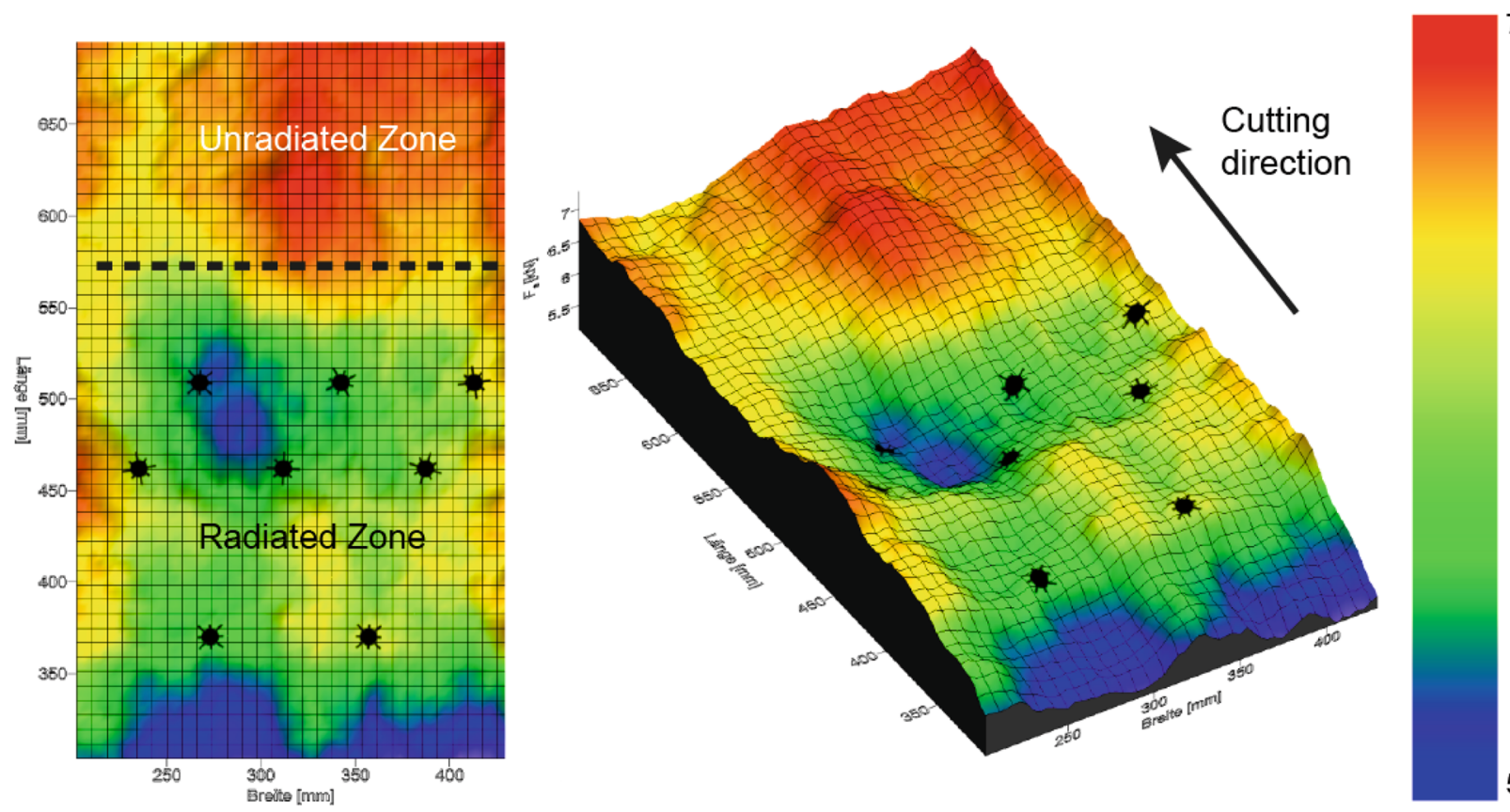

$7,3 \mathrm{kN}$

$6,0 \mathrm{kN}$

Figure 3: Floating median calculation of cutting forces for partly radiated granite block (Xand Y axis: surface of the block, Z-axis: moving average cutting force, search radius $=50 \mathrm{~mm}$ )

\subsection{Linear Cutting Test Rig}

The cutting test rig HSX-1000-50 was specifically produced and manufactured by the company ASW GmbH for TU Bergakademie Freiberg (Figure 2). It is used for carrying out comprehensive rock cutting tests aimed at the optimization of the rock cutting process (decreasing specific energy of rock destruction, maximizing cutting output, reducing wear and tear of cutting tools, reduction of dust and noise emissions). Programmable movement of a table with a sample in cutting direction, the $X$-axis, and of the tool holder in the respective $Y$ and $Z$-axes enables cutting tests to be carried out in a wide range of cutting parameters and trajectories. The relatively big size of rock samples (of up to $60 \times 120 \times 50 \mathrm{~cm}$ ) provides high precision and reliability of given results. The rig is equipped with a laser surface scanner, which extends scientific issues to be solved. The power of $60 \mathrm{~kW}$, flexible operating modes and modular design of HSX-1000-50 allows for different types of cutting tools to be tested. In operation mode, cutting and penetration forces of up to $50 \mathrm{kN}$ can be measured with piezo sensors at a maximum sampling rate of $10,000 \mathrm{kHz}$ while the maximum cutting speed lies at $1.7 \mathrm{~m} / \mathrm{s}$.

\section{Results}

Microwave irradiation leads to heating of the irradiated spots to surface temperatures of approximately $150^{\circ} \mathrm{C}$. It is assumed that the temperature beneath the surface is significantly higher (compare also [10]). The resulting crack pattern can be seen in Figure 1. A number of cracks are 


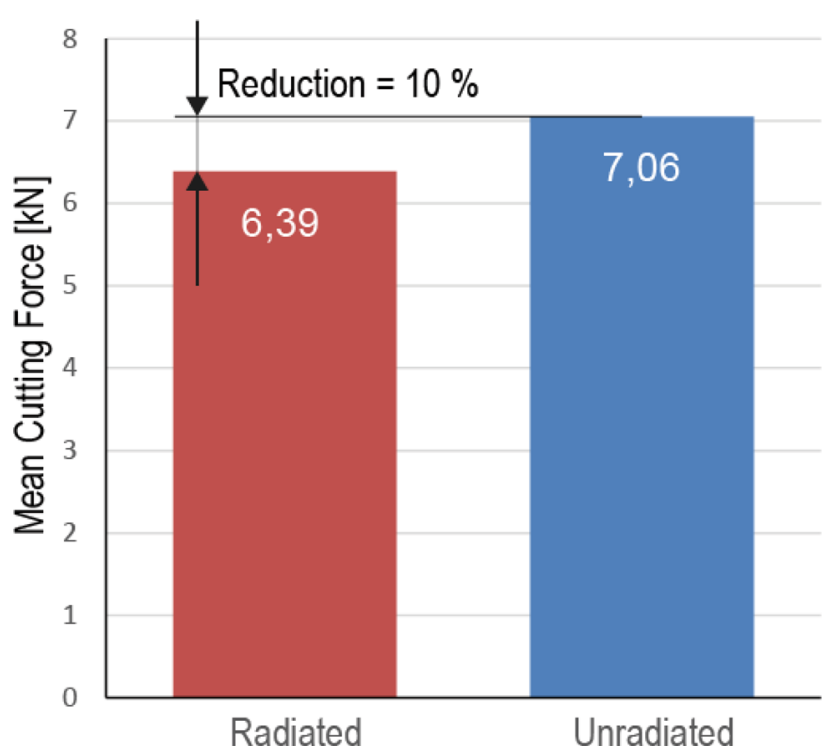

Figure 4: Mean cutting force and its reduction comparing radiated and untreated part of specimen

emerging from every single irradiation spot leading to an extensive cracks pattern all over the sample.

Linear cutting tests performed on an irradiated rock sample reveal a reduction of cutting forces associated with the microwave irradiation at a cutting depth of $4 \mathrm{~mm}$ with a spacing of $8 \mathrm{~mm}$. Figure 3 shows the cutting forces acting on the pick when stripping one layer of granite. The figure shows a false coloured surface displaying the cutting forces as a function of the $X-Y$ position of the pick on the samples surface. To enhance visibility, the forces are smoothed using a moving average interpolation with a search radius of $50 \mathrm{~mm}$. Black dots are highlighting the irradiated spots. The differences between the irradiated and the untreated parts of the block are clearly visible from these pictures. One can see that the entire area influenced by microwave irradiation shows reduced cutting forces when compared to the untreated area.

The cutting forces therefore range between $5.1 \mathrm{kN}$ in the weakest to $7.3 \mathrm{kN}$ in the toughest parts. As seen in Figure 4, the average cutting forces are 7.06 and $6.39 \mathrm{kN}$ in untreated and irradiated part, respectively. This is equivalent to a reduction of $10 \%$ caused by microwave irradiation.

\section{Discussion}

It was already demonstrated by Restner and Gehring [11] that a change in rock mass properties, especially the Rock Mass Rating (RMR), will have a significant influence on the net cutting rate of and the specific pick consumption when cutting hard rocks. Microwave irradiation of a rock mass produced a number of artificial cracks, both on a macroscopic and a microscopic scale. Cracks can be caused by differential heating at grain boundaries, especially in the vicinity of the microwave beam. This was demonstrated for multiple rock types and ores in literature where extensive cracking on a grain-scale is reported for magnesite, an- desite, dolomite and siderite [12] and a range of copper and lead-zinc ores (e.g. $[13,14])$. Particularly the positive effect for copper processing was reported by various authors, e.g. [15-17]. The presented results show that a range of larger cracks can also be introduced in some distance to the irradiation spot. Presumably this is due to stresses originating in the centre which are not just associated to different microwave absorption properties but also to physical phase changes like elongation of minerals under temperature load $[6,18]$.

The sum of these cracks represents a considerable reduction of RMR in the presented case, leading to a reduction of required cutting forces of approximately $10 \%$ in the irradiated parts of a rock sample compared to the untreated parts of the very same sample.

\section{Conclusions}

In this paper we demonstrate the influence of microwave irradiation of granite, representing a typical hard rock, on the forces acting on a conical pick when cutting this rock in a linear cutting test rig. Thirty Seconds of microwave irradiation with $24 \mathrm{~kW}$ power in a chessboard-like pattern leads to a reduction of cutting forces by approximately $10 \%$. Furthermore, the technology shows numerous potential optimization points. Radiation times, spacing of radiation spots, adjustment of frequency can greatly increase the efficiency of a microwave treatment preceding mechanical excavation.

Open access funding provided by Montanuniversität Leoben.

Open Access This article is distributed under the terms of the Creative Commons Attribution 4.0 International License (http://creativecommons. org/licenses/by/4.0/), which permits unrestricted use, distribution, and reproduction in any medium, provided you give appropriate credit to the original author(s) and the source, provide a link to the Creative Commons license, and indicate if changes were made.

\section{References}

1. Santamarina, J. C. (ed.): Rock excavation with microwaves: a literature review, Evanston, IL (etc.): Publ by ASCE, 1989.

2. Ali, A. Y.; Bradshaw, S. M.: Confined particle bed breakage of microwave treated and untreated ores, Minerals Engineering 24 (2011), no.14, pp 1625-1630.

3. Jones, D. A.; Kingman, S. W.; Whittles, D. N.; Lowndes, I. S.: Understanding microwave assisted breakage, Minerals Engineering 18 (2005), no.7, pp 659-669.

4. Meisels, R.; Toifl, M.; Hartlieb, P.; Kuchar, F.; Antretter, T.: Microwave propagation and absorption and its thermo-mechanical consequences in heterogeneous rocks, International Journal of Mineral Processing 135 (2015), pp 40-51.

5. Toifl, M.; Meisels, R.; Hartlieb, P.; Kuchar, F; Antretter, T.: Microwave absorption and its thermo-mechanical consequences in heterogeneous rocks, in: Soga, K.; Kumar, K.; Biscontin, G.; Kuo, M. (eds.): Geomechanics from micro to macro, Crc Press, 2014, pp 1545-1550.

6. Toifl, M.; Meisels, R.; Hartlieb, P.; Kuchar, F.; Antretter, T.: 3D numerical study on microwave induced stresses in inhomogeneous hard rocks, Minerals Engineering (2016), no.90, pp 29-42.

7. Wang, G.; Radziszewski, P.; Ouellet, J.: Particle modeling simulation of thermal effects on ore breakage, Computational Materials Science 43 (2008), no.4, pp 892-901. 
8. Wang, Y.; Djordjevic, N.: Thermal stress FEM analysis of rock with microwave energy, International Journal of Mineral Processing 130 (2014), pp 74-81.

9. Fitzgibbon, K. E.; Veasey, T. J.: Thermally assisted liberation - a review, Minerals Engineering 3 (1990), no.1, pp 181-185.

10. Hartlieb, P.; Leindl, M.; Kuchar, F.; Antretter, T.; Moser, P.: Damage of basalt induced by microwave irradiation: Special Issue - Physical Separation, Minerals Engineering 31 (2012), pp 82-89.

11. Restner, U.; Gehring, K.: Quantification of rock mass influence on cuttability with roadheaders, in: Proceedings TUR 2002, $2^{\text {nd }}$ International Conference on Mining Techniques, Krakow - Krynica, 2002, pp 53-68.

12. Murová, I.; Lovás, M.; Jakabský, S.: The influence of microwave radiation on the failure of rocks, Acta Montanistica Slovaca 5 (2000), no.3, pp 283-285.

13. Vorster, W.; Rowson, N. A.; Kingman, S. W.: The effect of microwave radiation upon the processing of Neves Corvo copper ore, International Journal of Mineral Processing 63 (2001), no.1, pp 29-44.

14. Kingman, S. W.; Jackson, K.; Cumbane, A.; Bradshaw, S. M.; Rowson, N. A.; Greenwood, R.: Recent developments in microwave- assisted comminution, International Journal of Mineral Processing 74 (2004), 1-4, pp 71-83.

15. Batchelor, A. R.; Jones, D. A.; Plint, S.; Kingman, S. W.: Increasing the grind size for effective liberation and flotation of a porphyry copper ore by microwave treatment, Minerals Engineering 94 (2016), pp 61-75.

16. Rizmanoski, V.: The effect of microwave pretreatment on impact breakage of copper ore, Minerals Engineering 24 (2011), no.14, pp 1609-1618.

17. Didenko, A.; Kozlov, E.; Sharkeev, Y.; Sulakshin, A.; Filipenko, N.; Girsova, N.; Fortuna, S. M. Y. V.: Formation of the defective structure in copper under the effect of powerful pulsed microwave radiation, Physics and Chemistry of Materials Treatment 31 (1997), no.5, pp 441-446.

18. Hartlieb, P.; Toifl, M.; Kuchar, F.; Meisels, R.; Antretter, T.: Thermophysical properties of selected hard rocks and their relation to microwave-assisted comminution, Minerals Engineering 91 (2016), pp 34-41. 